Research Article

\title{
A Probabilistic Assessment Model for Train-Bridge Systems: Special Attention on Track Irregularities
}

\author{
Dejun Liu $\mathbb{D}$, ${ }^{1}$ Lifeng Xin $\mathbb{D}^{2},{ }^{2}$ Xiaozhen Li $\mathbb{D},{ }^{3}$ and Jiaxin Zhang $\mathbb{D}^{3}$ \\ ${ }^{1}$ College of Civil Engineering \& Architecture, Jiaxing University, Jiaxing, China \\ ${ }^{2}$ School of Mechanics, Civil Engineering \& Architecture, Northwestern Polytechnical University, Xi'an, China \\ ${ }^{3}$ Department of Bridge Engineering, Southwest Jiaotong University, Chengdu, China \\ Correspondence should be addressed to Lifeng Xin; sxxlf2010@163.com
}

Received 15 April 2021; Accepted 30 July 2021; Published 17 August 2021

Academic Editor: Changjie Zheng

Copyright (C) 2021 Dejun Liu et al. This is an open access article distributed under the Creative Commons Attribution License, which permits unrestricted use, distribution, and reproduction in any medium, provided the original work is properly cited.

In this paper, a probabilistic model devoted to investigating the dynamic behaviors of train-bridge systems subjected to random track irregularities is presented, in which a train-ballasted track-bridge coupled model with nonlinear wheel-rail contacts is introduced, and then a new approach for simulating a random field of track irregularities is developed; moreover, the probability density evolution method is used to describe the probability transmission from excitation inputs to response outputs; finally, extended analysis from three aspects, that is, stochastic analysis, reliability analysis, and correlation analysis, are conducted on the evaluation and application of the proposed model. Besides, compared to the Monte Carlo method, the high efficiency and the accuracy of this proposed model are validated. Numerical studies show that the ergodic properties of track irregularities on spectra, amplitudes, wavelengths, and phases should be taken into account in stochastic analysis of train-bridge interactions. Since the main contributive factors concerning different dynamic indices are rather different, different failure modes possess no obvious or only weak correlations from the probabilistic perspective, and the first-order reliability theory is suitable in achieving the system reliability.

\section{Introduction}

The accurate and reliable numerical estimation of rolling stocks passing over high-speed railway bridges is an important and cheap means to optimize the bridge design, improve the operation quality, and enhance the profitability of railway systems. However, the existence of uncertainties, which originate from the controllable or uncontrollable construction errors, environmental impact, and long-term natural evolution, seriously reduces the authority and persuasiveness of conventional deterministic numerical prediction. Against this backdrop, the dynamic assessment of train-bridge interaction system from the probabilistic perspective is being urgently sought.

For obtaining the full view of dynamic behaviors of train-bridge systems, much attention should be first given to the variability of track irregularities due to its great importance in the interaction. Until now, the statistically average power spectral density (PSD) is a common way to represent the track irregularities [1-3], based on which track irregularity sets with spatial randomness can be easily generated through some time-frequency transformation approaches $[4,5]$. However, the average track spectrum, which just represents such limited track profile deformations, is insufficient to describe the complete track-geometry variations in a railway line. In last decades, many scholars have focused on the modelling techniques of the track irregularity random field. For instance, Zhu et al. [6] considered track vertical profile and alignment irregularities as Gaussian process and studied the levelcrossing properties and peak statistics by comparing with the measurements. Perrin et al. [7-9] presented the track irregularity stochastic model by introducing approaches of Karhunen-Loéve expansion and polynomial chaos expansion, in which the statistical properties of this vectorvalued, non-Gaussian, and nonstationary track 
irregularity random field were properly considered and most importantly the dependencies of irregularities were taken into account. This technique was also applied into the French urban railway network [10]. Xu and Zhai $[11,12]$ provided new insights into the probabilistic characteristics of track irregularity PSDs on the basis of the intrinsic features of track irregularities in the shape similarity of PSD functions and derived a spectral-based method to inversely and efficiently simulate the random track irregularities with ergodic properties. From the aforementioned studies, it can be seen that the methodologies for simulating random track irregularities are gradually advancing toward maturities.

In the last decades, research studies on the dynamic behaviors of track irregularity-induced train-bridge systems under have gradually been extended from the deterministic analysis to the probabilistic analysis. For example, Chatterjee et al. [13], Au et al. [14], Xia et al. [15], and Liu et al. [16, 17] used multiple samples of track irregularities from one PSD to explore the effects of the location of irregularity amplitudes on system responses. By applying the pseudoexcitation method (PEM), researchers can efficiently study the random vibrations of train-bridge systems, where random irregularities were transformed into the superposition of a series of deterministic pseudoharmonic signals [18-21]. Rocha et al. $[22,23]$ took the assumption that the track spectra are uniformly distributed and employed the Monte Carlo simulation and tail modelling technique to assess the track stability caused by excessive deck vibrations and running safety of trains for a short-span railway bridge. Subsequently, with the same assumption, they [24] tested the efficiencies of some typical sampling methods and compared their differences in estimating the probability of failure. Salcher et al. [25] also assumed that the track spectra are uniformly distributed and conducted an interesting work in the codebased reliability evaluation of train-bridge systems, in which the uncertainties of bridge, track, vehicle, track irregularity, and environmental impact are fully included. Mao et al. $[26,27]$ used the probability density evolution method to perform random dynamic analysis of train-bridge systems subjected to random track irregularities with one PSD and system parameters. Jin et al. [28] applied the spectral method to obtain the random vibration of bridges due to a series of moving forces in frequency domain, and the hunting forces are modelled as a random process with the given PSD instead of harmonic forces. Cantero et al. [29] investigated the influences of wavelength ranges of track irregularities on train-bridge systems. In the above studies, abundant meaningful conclusions have been achieved. However, track irregularity PSDs were usually assumed to be uniformly distributed due to the scarcity of measurements, and therefore, the variability of track irregularity was not scientifically considered in the studies. Moreover, the majority of these investigations have simplified the wheel-rail interaction relationship to different levels for efficiency. This may lead to insufficient understandings. Currently, systematic work has rarely been reported in evaluating a relatively complete train-bridge system under random track irregularity from the probabilistic perspective.
This paper aims to develop a probabilistic model to comprehensively assess the dynamic performance of trackbridge coupled systems under track random irregularities. First, a three-dimensional (3D) train-ballasted track-bridge model is introduced, in which the nonlinear wheel-rail contact relationship and the mechanics of different components are covered. Second, the approach in simulating the random field of track irregularities is presented, and the ergodic properties are entirely considered in the temporalspatial domain. Then, the probability density evolution method (PDEM) is introduced to solve the probabilistic transmission between excitation inputs and response outputs. Finally, some significant aspects are investigated to reveal the random behaviors, including stochastic analysis, reliability analysis, and probabilistic relation analysis.

\section{Introduction of Train-Track-Bridge Model}

The train-track-bridge coupled system can be decomposed into three subsystems, namely, subsystems of the train, the track, and the bridge, which are spatially coupled by nonlinear wheel-rail interactions and track-bridge interactions, as shown in Figure 1. Without the loss of generality, the dynamic equations of motion for the coupled system can be written in the following form [31]:

$$
\begin{aligned}
\mathbf{M}_{n} \ddot{X}_{n}+\mathbf{C}_{n} \dot{X}_{n}+\mathbf{K}_{n} \mathbf{X}_{n} & =\mathbf{F}_{n}, \\
\mathbf{M}_{t} \ddot{X}_{t}+\mathbf{C}_{t} \dot{X}_{t}+\mathbf{K}_{t} \mathbf{X}_{t} & =\mathbf{F}_{t}, \\
\mathbf{M}_{b} \ddot{X}_{b}+\mathbf{C}_{b} \dot{X}_{b}+\mathbf{K}_{b} \mathbf{X}_{b} & =\mathbf{F}_{b},
\end{aligned}
$$

where $\mathbf{M}, \mathbf{C}$, and $\mathbf{K}$ are mass, damping, and stiffness submatrices, respectively; the subscripts " $n$," " $t$," and " $b$ " represent the submodules of the vehicle, the track, and the bridge, respectively, and $\ddot{X}, \dot{X}, \mathbf{X}$, and $\mathbf{F}$ are the vectors of acceleration, velocity, displacement, and force, respectively.

The modelling methods are summarized in Tables 1 and 2 .

\section{Random Field of Track Irregularities}

Rising from the manufacturing faultiness and environmental loads, e.g., cyclic wheel-rail interactions, material fatigue, and track settlement, track irregularities are characterized by high-dimensional randomicity in both spatial and temporal domains. Its spatial randomness behaves as the random distribution of amplitudes and phases along the track, and the temporal randomness is represented by the fluctuation of spectral lines, as shown in Figure 2. Xu and Zhai $[11,12]$ pointed out that the ergodic properties of PSD probabilities, amplitudes, and wavelengths of track irregularities should be taken into account in the stochastic analysis of vehicle-track interactions and presented a track irregularity probabilistic model. However, being different from the repetitive feature of the train-track system, the dynamic response of train-bridge systems is dependent on the position of trains passing over the bridge. To completely consider the spatial randomness of track irregularities at every bridge position, the ergodic property of phases may also be considered in train-bridge systems. 


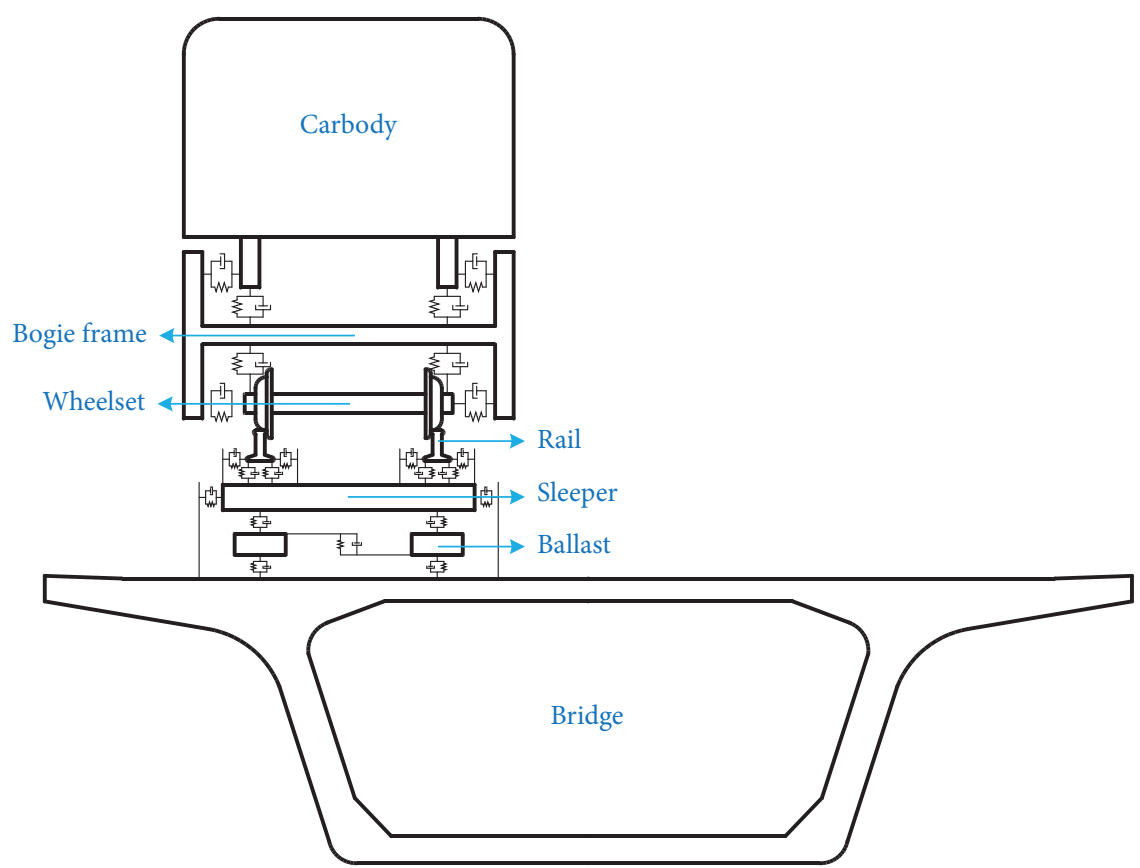

(a)

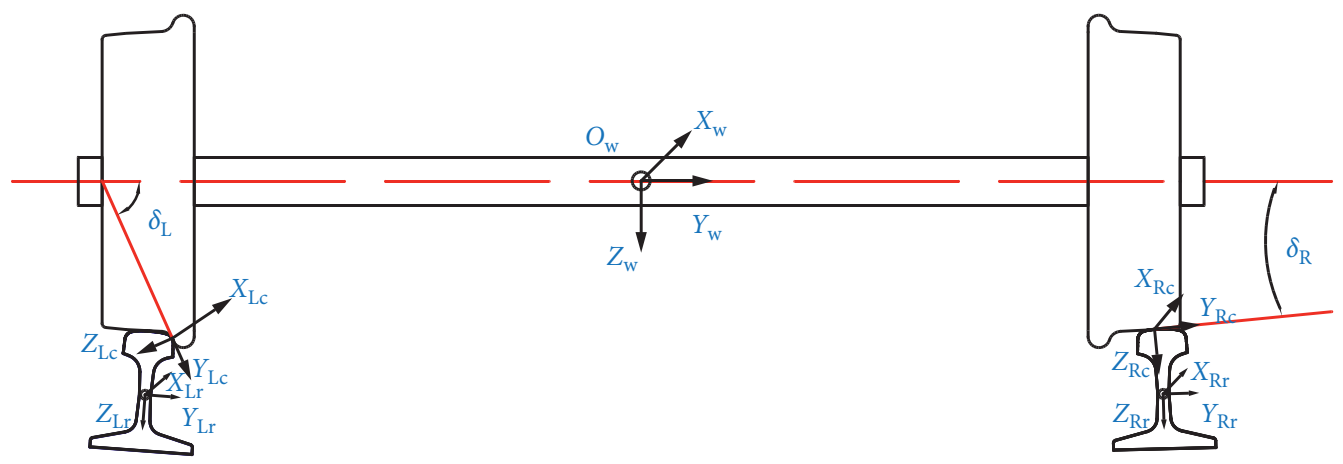

(b)

Figure 1: Train-track-bridge interaction model. (a) End view; (b) wheel-rail interactions [30].

In this paper, an extended approach is developed to characterize the ergodic properties of track irregularities on track spectrum, amplitudes, wavelengths, and phases based on the track irregularity probabilistic model proposed by Xu and Zhai $[11,12]$. The detailed modelling method is presented in the following sections.

3.1. PSD Probability Distribution. The approach on the PSD probability distribution of track irregularities from big data of measurements proposed by Xu and Zhai $[11,12]$ can be reconsidered as follows.

Let $\ell_{v}(k \Delta s)$ be a portion of track irregularities, where $k=1,2, \ldots, N ; \Delta s$ is the discrete spacing; $N$ is the total number of track irregularity segments; and $v$, $v=v_{1}, v_{2}, v_{3}, v_{4}$, represents the type of track irregularity, namely, vertical profile, alignment, cross level, and gauge, respectively. Define $\hbar(\cdot)$ as the PSD function operator, and then the PSD of $\ell_{v}(k \Delta s)$ can be conveniently derived by

$$
P_{v, k}(\omega)=\hbar\left(\ell_{v}(k \Delta s)\right)
$$

in which $\omega$ is the set of discrete frequency points with a total number of $W$.

Out of the analytical convenience, a spectral density matrix with the order of $N \times W$ can be assembled by

$$
\Omega_{v}(k, \omega)=\left[\begin{array}{cccc}
P_{v, 1}\left(\omega_{1}\right) & P_{v, 1}\left(\omega_{2}\right) & \ldots & P_{v, 1}\left(\omega_{W}\right) \\
P_{v, 2}\left(\omega_{1}\right) & P_{v, 2}\left(\omega_{2}\right) & \ldots & P_{v, 2}\left(\omega_{W}\right) \\
\ldots & \ldots & \ddots & \ldots \\
P_{v, N}\left(\omega_{1}\right) & P_{v, N}\left(\omega_{2}\right) & \ldots & P_{v, N}\left(\omega_{W}\right)
\end{array}\right],
$$

with $P_{v, l}\left(\omega_{d}\right)=\min \left[\Omega_{v}\left(k, \omega_{d}\right)\right] \quad$ and $\quad P_{v, u}\left(\omega_{d}\right)=\max$ $\left[\Omega_{v}\left(k, \omega_{d}\right)\right]$, where $\omega_{d}, d=1,2, \ldots, W$, is the discrete frequency point and $\min [\cdot]$ and $\max [\cdot]$ denote the minimum and maximum operators, respectively.

Since the spectral densities are discretely distributed, the amplitude domain of $P_{v}\left(\omega_{d}\right)$ can be divided into 
TABLE 1: Simulation of the train-ballasted track-bridge coupled system [31, 32].

\begin{tabular}{|c|c|c|c|c|c|c|}
\hline Items & Theory & Component & Number & $\begin{array}{l}\text { Modelling } \\
\text { method }\end{array}$ & Comment & Integration \\
\hline \multirow{4}{*}{ Train } & \multirow{4}{*}{ D'Alembert principle } & Carbody & 1 & Rigid body & $\begin{array}{l}\text { Lateral, roll, yaw, vertical, } \\
\text { and pitch motions }\end{array}$ & \multirow{4}{*}{ Zhai's method } \\
\hline & & Bogie frame & 2 & Rigid body & $\begin{array}{l}\text { Lateral, roll, yaw, vertical, } \\
\text { and pitch motions }\end{array}$ & \\
\hline & & Wheelset & 4 & Rigid body & $\begin{array}{l}\text { Lateral, roll, yaw, vertical, } \\
\text { and pitch motions }\end{array}$ & \\
\hline & & Suspension & $\begin{array}{c}2 \\
\text { stages }\end{array}$ & $\begin{array}{l}\text { Linear springs } \\
\text { and dampers }\end{array}$ & Three directions & \\
\hline \multirow{4}{*}{$\begin{array}{l}\text { Ballasted } \\
\text { track }\end{array}$} & \multirow{4}{*}{$\begin{array}{l}\text { D'Alembert principle and } \\
\text { mode superposition method }\end{array}$} & Rail & $*$ & $\begin{array}{l}\text { Bernoulli-Euler } \\
\text { beams }\end{array}$ & $\begin{array}{l}\text { Vertical, lateral, and } \\
\text { torsional vibrations }\end{array}$ & \multirow{4}{*}{ Zhai's method } \\
\hline & & Rail pad & $*$ & $\begin{array}{l}\text { Linear springs } \\
\text { and dampers }\end{array}$ & $\begin{array}{l}\text { Later and vertical } \\
\text { directions }\end{array}$ & \\
\hline & & Sleeper & $*$ & Rigid body & $\begin{array}{l}\text { Vertical, lateral, and } \\
\text { torsional vibrations }\end{array}$ & \\
\hline & & Ballast & $*$ & Mass blocks & $\begin{array}{c}\text { Lateral and vertical } \\
\text { directions }\end{array}$ & \\
\hline \multirow{4}{*}{ Bridge } & \multirow{4}{*}{ Finite element method } & Truss & * & Bar element & Three dimensions & \multirow{4}{*}{$\begin{array}{l}\text { Newmark- } \beta \text { implicit } \\
\text { integration method }\end{array}$} \\
\hline & & Beam & $*$ & Beam element & Three dimensions & \\
\hline & & Plate & * & $\begin{array}{l}\text { Four-node plate } \\
\text { element }\end{array}$ & Three dimensions & \\
\hline & & $\ldots$ & $*$ & $\ldots$ & $\ldots$ & \\
\hline
\end{tabular}

TABLE 2: Wheel-rail interactions and track-bridge interactions [30].

\begin{tabular}{lccc}
\hline Item & Issue & Direction & Theory or method \\
\hline $\begin{array}{l}\text { Wheel-rail } \\
\text { interactions }\end{array}$ & $\begin{array}{c}\text { Geometric } \\
\text { relation }\end{array}$ & - & 1D scanning method with the assumption of one-point contact \\
Contact force & $\begin{array}{c}\text { Normal direction } \\
\text { Tangential direction }\end{array}$ & $\begin{array}{c}\text { Nonlinear Hertz elastic contact theory } \\
\text { Modified Kalker's linear creep theory }\end{array}$ \\
\hline $\begin{array}{l}\text { Track-bridge } \\
\text { interactions }\end{array}$ & Contact force & $\begin{array}{c}\text { Lateral and vertical } \\
\text { direction }\end{array}$ & $\begin{array}{c}\text { A series of point-to-point interactions which are connected with linear } \\
\text { spring and damping at each contact point }\end{array}$ \\
\hline
\end{tabular}

$$
\left\{\begin{array}{l}
P_{v}\left(\omega_{d}\right)=\cup P_{v, q}\left(\omega_{d}\right), \quad 0 \leq q \leq Q-1, \\
P_{v, q}\left(\omega_{d}\right) \in\left[P_{v, l}\left(\omega_{d}\right)+q \widetilde{P}_{v}\left(\omega_{d}\right), P_{v, l}\left(\omega_{d}\right)+(q+1) \widetilde{P}_{v}\left(\omega_{d}\right)\right]
\end{array}\right.
$$

with $\widetilde{P}_{v}\left(\omega_{d}\right)=\operatorname{int}\left[P_{v, u}\left(\omega_{d}\right)-P_{v, l}\left(\omega_{d}\right) / Q\right]$, in which $\widetilde{P}$ is the discrete interval of spectral densities, $Q$ is the total partition number, and int [.] is an operator used to round the number in the bracket to the nearest integer toward minus infinity.

Based on probability statistics, the probability density function (PDF) of $P_{v}\left(\omega_{d}\right)$ can be expressed as follows:

$$
f_{v, \omega_{d}}=\lambda\left(P_{v}\left(\omega_{d}\right)\right)
$$

in which $\lambda(\cdot)$ is the PDF operator.

Owing to the shape similarity of PSD lines and probability equivalence, a cumulative probability index $U_{v} \in[0,1]$ is introduced to uniquely determine the value of spectral density over $P_{v}(\omega)$, namely,

$$
P_{v, \omega}^{\prime}\left(U_{v}\right)=F_{v, \omega_{d}}^{-1}\left(U_{v}\right)
$$

with $F_{v, \omega_{d}}(q)=\int_{-\infty}^{q} f_{v, \omega_{d}}(q) \mathrm{d} q$, in which $F_{v}(\cdot)$ is the cumulative probability function (CDF) of $f_{v}(\cdot)$.

The statistically average spectrum can be easily derived, namely,

$$
\bar{P}_{v}\left(\omega_{d}\right)=F_{v, \omega_{d}}^{-1}\left(\int_{0}^{1} f_{v, \omega_{d}}\left(U_{v}\right) \mathrm{d} U_{v}\right)
$$

As an illustration, Figure 3 plots the PDF of track vertical profile irregularity PSD against the cumulative probability index $U_{v}$. As recognized by the visual impression, the probability characteristic is definitely not uniformly distributed. The uniformly distributed assumption in previous studies [21-25] did not reflect the actual physical status. Meanwhile, it can be seen that the average track spectrum is approximately at the cumulative probability of 0.46 .

3.2. Time-Frequency Transformation. Let $T_{v, U_{i}}(x)$ be a onedimensional stationary random process to characterize the PSD of track irregularity at cumulative probability $U_{i}$, denoted by $P_{v, U_{i}^{\prime}}(\omega)$. As Shinozuka et al. [33] derived, $T_{v, U_{i}}(x)$ can be expressed by the following discrete integral form:

$$
T_{v, U_{i}}(x)=\sum_{k=0}^{\infty}\left[\cos \left(\omega_{k} x\right) \mathrm{d} u\left(\omega_{k}\right)+\sin \left(\omega_{k} x\right) \mathrm{d} v\left(\omega_{k}\right)\right],
$$

in which $\omega_{k}=k \Delta \omega$ where $\Delta \omega$ is the frequency interval; $u(\omega)$ and $v(\omega)$ are two mutually orthogonal real processes with 


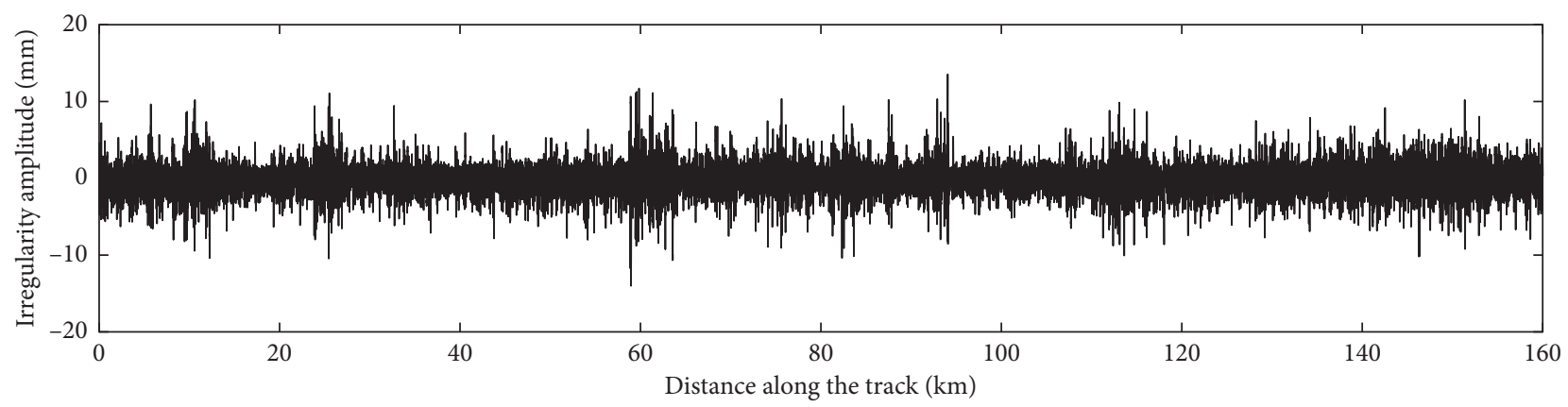

(a)

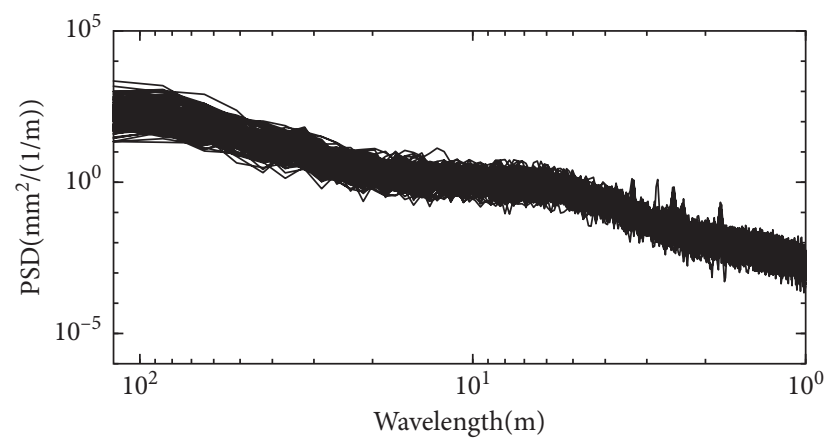

(b)

FIgURE 2: Field measured vertical profile irregularities: (a) in the spatial domain; (b) in the temporal domain.

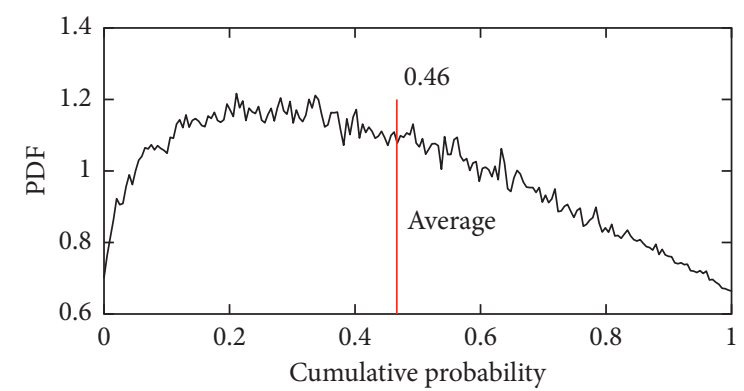

FIGURE 3: PDF distribution for the vertical profile PSD at different cumulative probabilities.

orthogonal increments $\mathrm{d} u(\omega)$ and $\mathrm{d} v(\omega)$; and $\mathrm{d} u\left(\omega_{k}\right)$ and $\mathrm{d} v\left(\omega_{k}\right)$ can be defined as follows:

$$
\begin{aligned}
& \mathrm{d} u\left(\omega_{k}\right)=A_{k} X_{k}, \\
& \mathrm{~d} v\left(\omega_{k}\right)=A_{k} Y_{k},
\end{aligned}
$$

with $A_{k}=\left(P_{v, U_{i}^{\prime}}^{\prime}(\omega) \Delta \omega\right)^{1 / 2}$, in which $\left\{X_{k}, Y_{k}\right\}$ is a group of orthogonal random variables and satisfies the conditions:

$$
\begin{aligned}
E\left[X_{k}\right] & =E\left[X_{k}\right]=0, \\
E\left[X_{j} Y_{k}\right] & =0, \\
E\left[X_{j} X_{k}\right] & =E\left[Y_{j} Y_{k}\right]=\delta_{j k},
\end{aligned}
$$

where $E[\cdot]$ is the operator of mathematical expectation and $\delta_{j k}$ is the Kronecker symbol.
Therefore, equation (8) can be approximately transformed into the sum of $M$ terms:

$$
T_{v, U_{i}}(x)=\sum_{k=1}^{M} A_{k}\left[\cos \left(\omega_{k} x\right) X_{k}+\sin \left(\omega_{k} x\right) Y_{k}\right] .
$$

To further reduce the random parameters of $T_{v, U_{i}}(x)$ and improve the efficiency of stochastic analysis, a method expressing the random variables $\left\{X_{k}, Y_{k}\right\}$ as random functions is developed by Liu et al. [34]. The procedure of realization can be expressed as follows:

(1) Generate the independent random variables $\left\{\theta_{1}, \theta_{2}\right\}$, which are uniformly distributed within $(0, t 2 \pi]$.

(2) Construct two sets of Gaussian, standard, orthonormal, and independent random variables, that is,

$$
\begin{aligned}
& \widetilde{X}_{m}=\Phi^{-1}\left[\frac{1}{2}+\frac{1}{\pi} \arcsin \left(\frac{\operatorname{cas}\left(n \theta_{1}\right)}{\sqrt{2}}\right)\right], \\
& \widetilde{Y}_{m}=\Phi^{-1}\left[\frac{1}{2}+\frac{1}{\pi} \arcsin \left(\frac{\operatorname{cas}\left(n \theta_{2}\right)}{\sqrt{2}}\right)\right],
\end{aligned}
$$

where $\operatorname{cas}(\cdot)=\cos (\cdot)+\sin (\cdot) ; \Phi^{-1}(\cdot)$ is the inverse function of standard normal distribution; and $m=1,2, \ldots, M$.

(3) Conduct a random mapping process, namely, $\left\{\widetilde{X}_{k}, \widetilde{Y}_{k}\right\} \longrightarrow\left\{X_{k}, Y_{k}\right\}$, and substitute it to equation (11). 
With above theoretical derivations, the degree of random process $T_{v, U_{i}}(x)$ has been reduced from infinity to $2 M$ and to 2 , namely, $\left\{\theta_{1}, \theta_{2}\right\}$.

As an example, Figure 4(a) shows two track irregularity series derived from one spectral representation, and Figure 4(b) depicts the corresponding PSDs. The wavelengths are in the range of $0.5-120 \mathrm{~m}$. It can be seen that the excellent agreement has been achieved between the simulating PSDs and the target PSD. Also, one can observe that the amplitudes in one position are significantly different due to the phase randomness. Figure 4(c) plots the mean values with 89 track irregularity samples obtained by the method in this paper. It can be seen that the mean values along the abscissa approach the ideal number, zero. The ergodic properties of track irregularities on amplitudes, wavelengths, and phases have been covered in this section.

3.3. Temporal-Spatial Track Random Irregularity. By combining Sections 3.1 and 3.2, a comprehensive random field of track irregularity in the temporal and spatial domain has been constructed, in which the variables should be investigated in a synergetic and coupled manner, that is,

$$
\mathbf{R}=\left(U_{v 1}, \theta_{v 1,1}, \theta_{v 1,2}, U_{v 2}, \theta_{v 2,1}, \theta_{v 2,2}, U_{v 3}, \theta_{v 3,1}, \theta_{v 3,2}, U_{v 4}, \theta_{v 4,1}, \theta_{v 4,2}\right) \text {. }
$$

Using some selecting point methods, such as Monte Carlo method (MCM), the number theoretical method [35], and Latin hypercube sampling (LHS) [36], the representative samples in the random field can be effectively generated.

For validation, comparisons are made of PDFs and CDFs obtained from the measured and simulated vertical profile irregularities. As can be seen from Figure 5, there is excellent agreement between them, which serves to illustrate the reliability of the proposed model.

\section{Analysis Framework for System Probabilistic Analysis}

In the following two sections, a PDEM developed by $\mathrm{Li}$ and Chen $[37,38]$ is introduced to achieve the probabilistic transmissions between the system inputs and the response outputs. Besides, an analysis framework for the probabilistic assessment of train-bridge systems under random temporalspatial track irregularities will be presented in detail.

4.1. PDEM. Correspondingly, the kinematic equations of the train-bridge system under random track irregularities can be transformed into the following form:

$$
\mathbf{M}_{s} \ddot{X}(t)+\mathbf{C}_{s} \dot{X}(t)+\mathbf{K}_{s} \mathbf{X}(t)=\mathbf{F}_{s}(\boldsymbol{\Theta}, t),
$$

where $\mathbf{M}_{s}, \mathbf{C}_{s}$, and $\mathbf{K}_{s}$ are the mass, damping, and stiffness matrices of the dynamic system, respectively; $\mathbf{X}(t), \dot{X}(t)$, and $\ddot{X}(t)$ are the state vectors of displacement, velocity, and acceleration, respectively; $\mathbf{F}_{s}(\Theta, t)$ is the load vectors including the random nonlinear wheel-rail interaction; and $\Theta$ is the random factors, herein, $\Theta=\mathbf{R}$.
The solution of equation (14) is completely and continuously dependent on the random parameters $\Theta$ and can be expressed as a function of them $[37,38]$ :

$$
X(t)=H(\Theta, t),
$$

Then, the velocity of $X(t)$, namely, the derivative of $X(t)$ with respect to time, can be written as follows:

$$
\begin{aligned}
\dot{X}(t) & =\frac{\partial H(\boldsymbol{\Theta}, t)}{\partial t} \\
& =h(\boldsymbol{\Theta}, t) .
\end{aligned}
$$

in which $h(\cdot)$ is the derivative of $H(\cdot)$ with respect to time.

From the Lagrangian viewpoint, as long as random events neither appear nor disappear, the associated probabilities will remain constant; in other words, the probability will be preserved in the evolution process of the system $[37,38]$. Based on the principle of the preservation of probability, the joint PDF of the augmented vector $(X(t), \Theta)$ will follow the generalized probability density evolution function:

$$
\frac{\partial p_{X \Theta}(x, \boldsymbol{\theta}, t)}{\partial t}+h(\boldsymbol{\theta}, t) \frac{\partial p_{X \Theta}(x, \boldsymbol{\theta}, t)}{\partial x}=0 .
$$

under the initial condition:

$$
\left.p_{X \Theta}(x, \boldsymbol{\theta}, t)\right|_{t=t_{0}}=\delta\left(x-x_{0}\right) p_{\Theta}(\boldsymbol{\theta}),
$$

where $\delta(\cdot)$ is the Dirac delta function, $x_{0}$ is the deterministic initial value, and $p_{\Theta}(\theta)$ is the joint probability of the random variables.

Equation (17) can be solved by a total variation diminishing (TVD) scheme $[37,38]$ in conjunction with equation (15), and then the instantaneous PDF of $X(t)$ can be obtained as follows

$$
p_{X}(x, t)=\int p_{X \Theta}(x, \boldsymbol{\theta}, t) \mathrm{d} \boldsymbol{\theta} .
$$

Once the PDF of dynamic indices is obtained, the reliability of which, $R_{X}(t)$, can be acquired consequently by

$$
R_{X}(t)=\int_{x_{l}}^{x_{u}} p_{X}(x, t) \mathrm{d} x
$$

in which $x_{l}$ and $x_{u}$ indicate the lower and upper bound of the dynamic index $X(t)$, respectively.

4.2. Analysis Framework. Based on the work illustrated above, a framework shown in Figure 6 for analyzing the effects of track irregularities on train-track interactions can be constructed.

\section{Applications}

In the numerical examples, it is assumed that the train runs with a constant velocity of $300 \mathrm{~km} / \mathrm{h}$ on a five-span simply supported concrete bridge with a length of $32 \mathrm{~m}$ for each span. This type of structural system is very common on Chinese high-speed railway lines. The box girder has a 


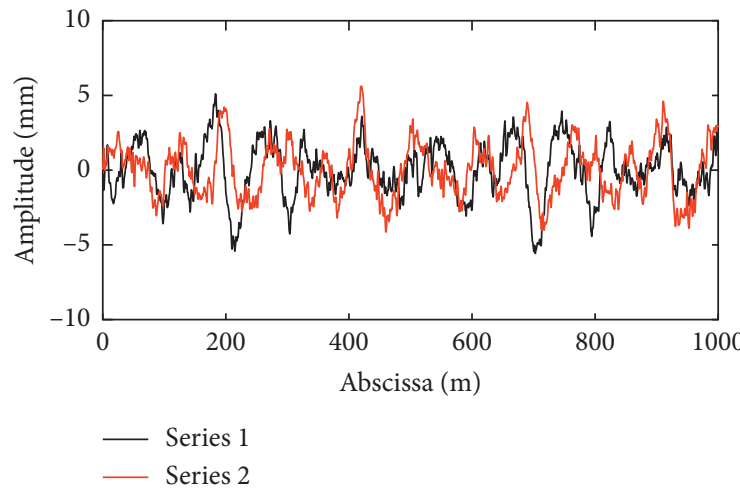

(a)

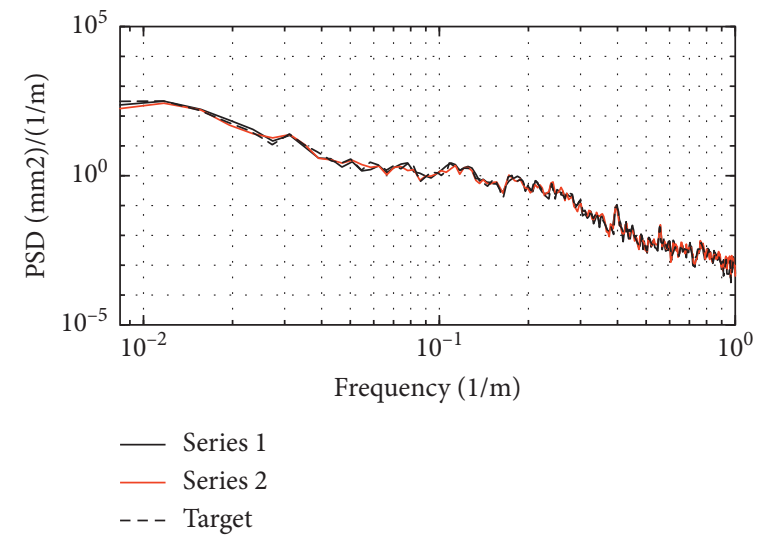

(b)

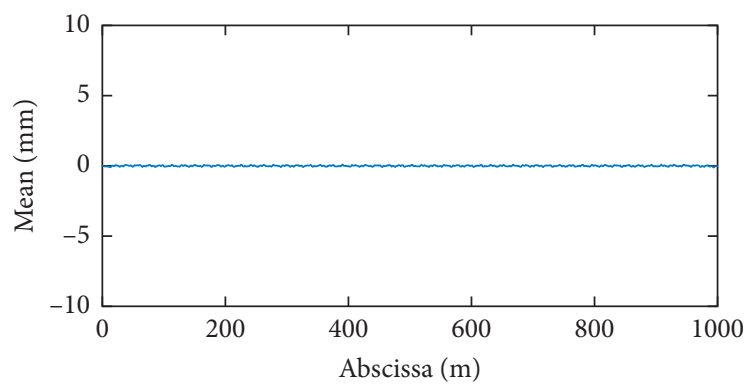

(c)

Figure 4: Transformation between frequency-domain PSDs and time-domain track irregularities: (a) time-domain track irregularities; (b) track irregularity PSD functions; (c) mean values with 89 samples.

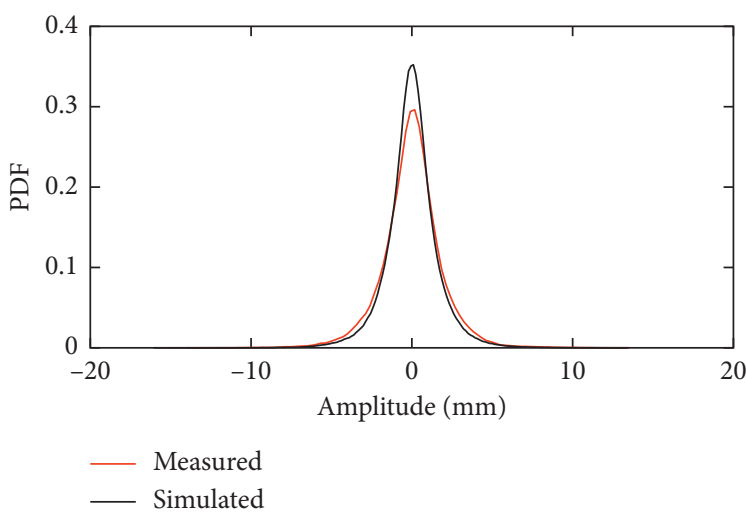

(a)

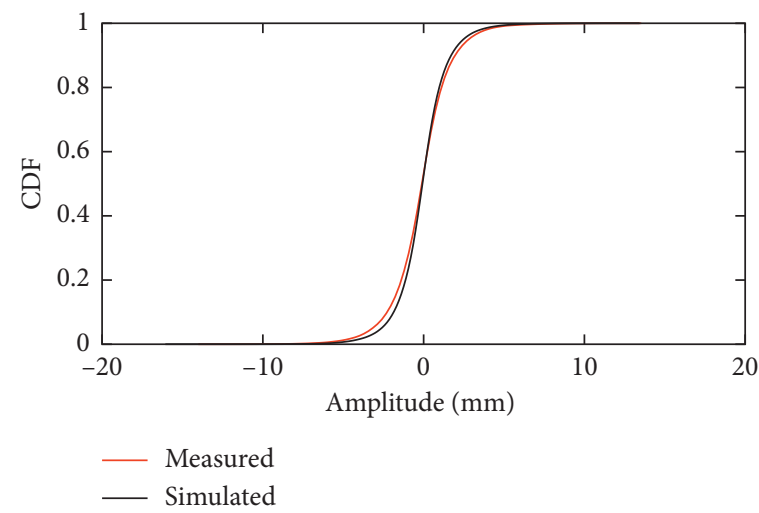

(b)

FIGURE 5: Comparison of statistical quantities between measured and simulated vertical profile irregularities: (a) PDF; (b) CDF.

unified section with a width of $11.6 \mathrm{~m}$ and a double-line railway. The box girder is made of reinforced concrete with a modulus of $3.5 \times 10^{4} \mathrm{MPa}$ and a density of $2549 \mathrm{~kg} / \mathrm{m}^{3}$. The piers, with hollow sections, are made of $\mathrm{C} 30$ with a modulus of $3.0 \times 10^{4} \mathrm{MPa}$ and a density of $2549 \mathrm{~kg} / \mathrm{m}^{3}$. The height of the piers is set at $15 \mathrm{~m}$. The sectional shapes are displayed in Figure 7. The connections between the beam ends and pier tops are represented by master-slave constraints. The damping ratio is set at 0.05 . An ICE-3 train is used as the train model. The train comprises eight cars: the first, third, sixth, and eighth are tractors and the second, fourth, fifth, and seventh are trailers. The detailed parameters of the vehicles and tracks used in the calculation can be consulted in reference [3]. The random track irregularities from the simulations in Section 3 are used as the excitations.

5.1. Numerical Validation. By postprocessing the responses of the dynamic indices using PDEM, the probability density surface of any arbitrary response index can be determined, 


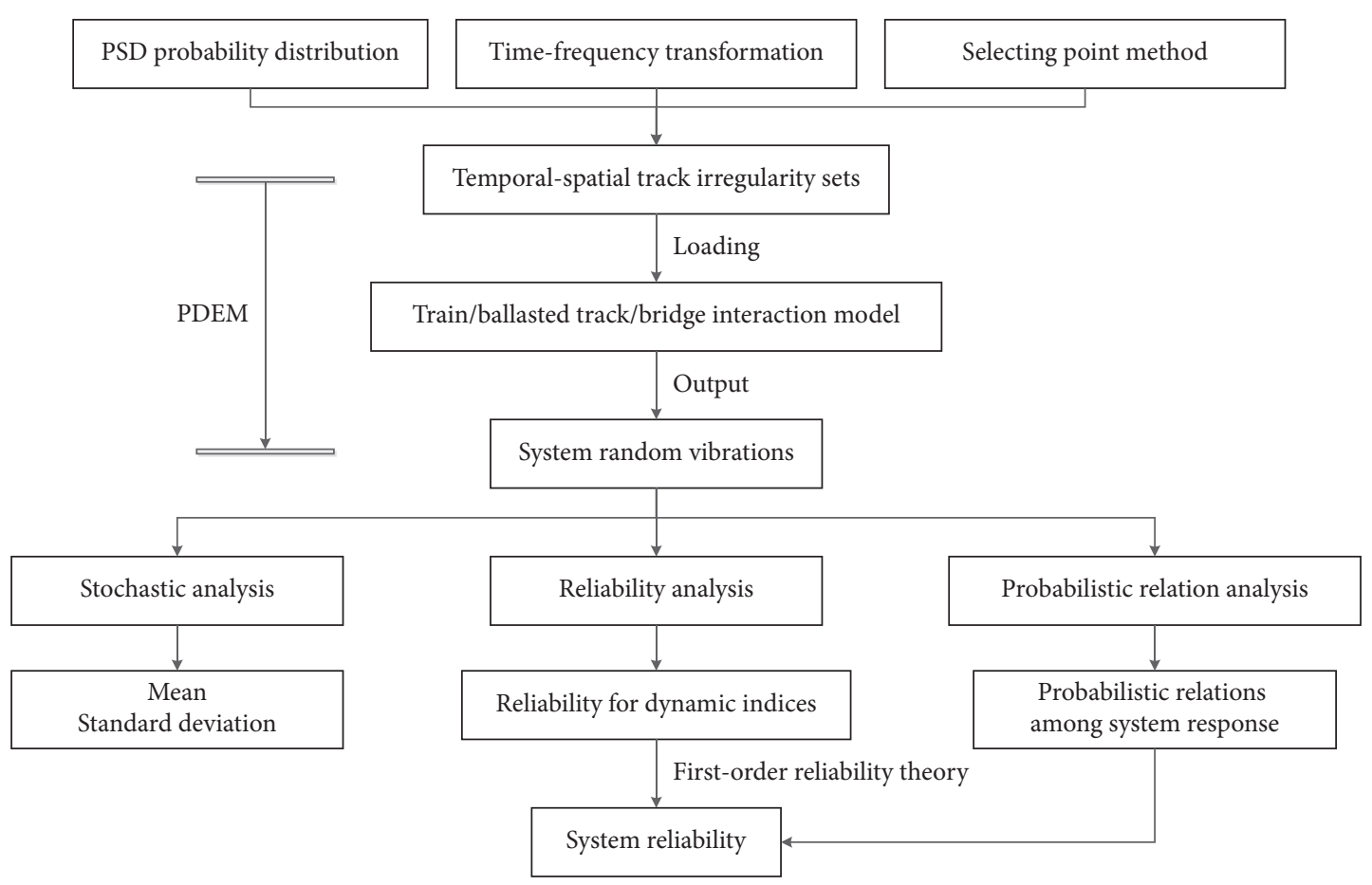

FIGURE 6: Analysis framework for probabilistic assessment of train-track systems under track irregularities.

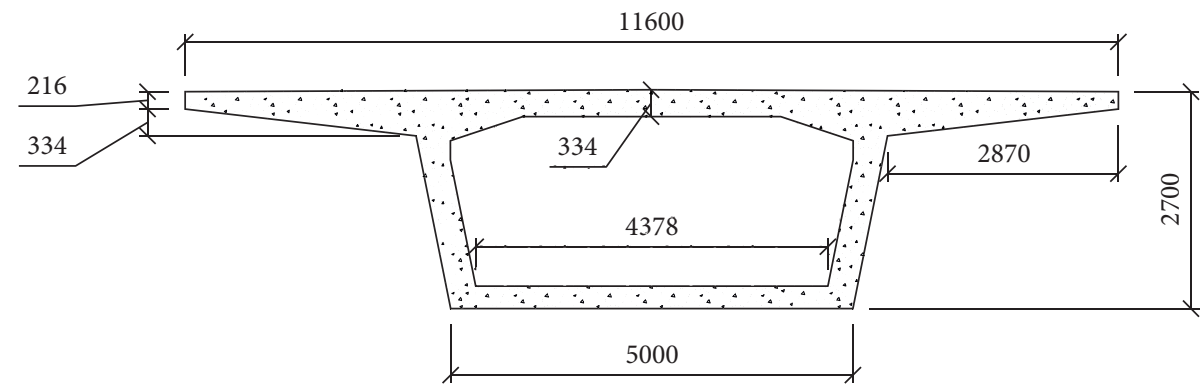

(a)

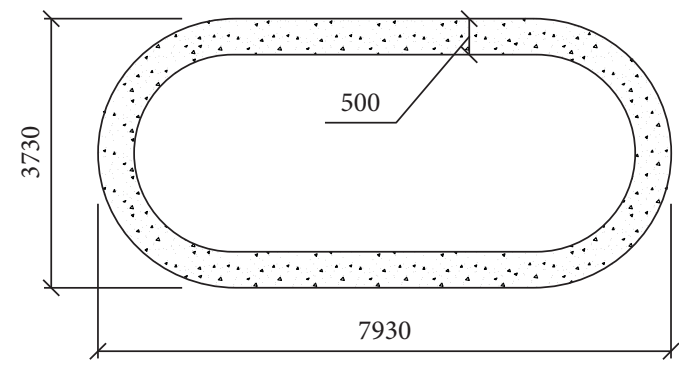

(b)

Figure 7: Cross section of the bridge (units: $\mathrm{mm}$ ): (a) beam; (b) pier.

from which the mean and standard deviation (Std. D) can be easily derived. In the validation, a rather robust method, MCM, is applied to prove the high precision and efficiency of the probabilistic model. For MCM, 12000 samples of the track random irregularities are selected. Moreover, 3000 samples are implemented to PDEM.

Figures 8(a)-8(c) show the probability density evolution against time, time-varying mean, and Std. D toward vertical carbody accelerations under track random irregularities, respectively. It can be observed that no matter on the statistical means or on Std. D against time, PDEM coincides well with the MCM though with very slight deviations. Therefore, it can be concluded that for the same accuracy level, PDEM is of much higher computational efficiency than MCM. Moreover, Figure 8(d) shows the results of vertical carbody accelerations without track 


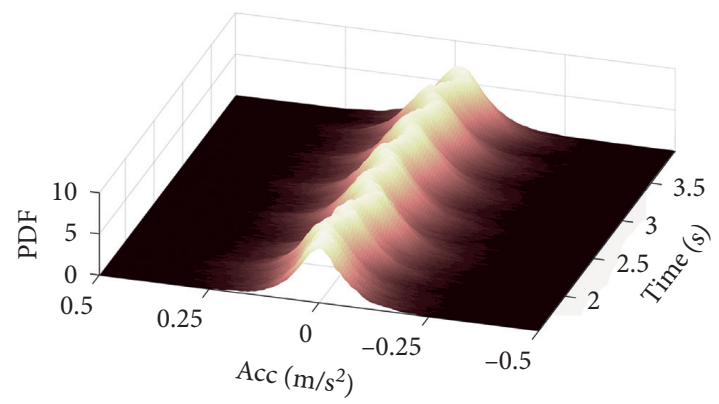

(a)

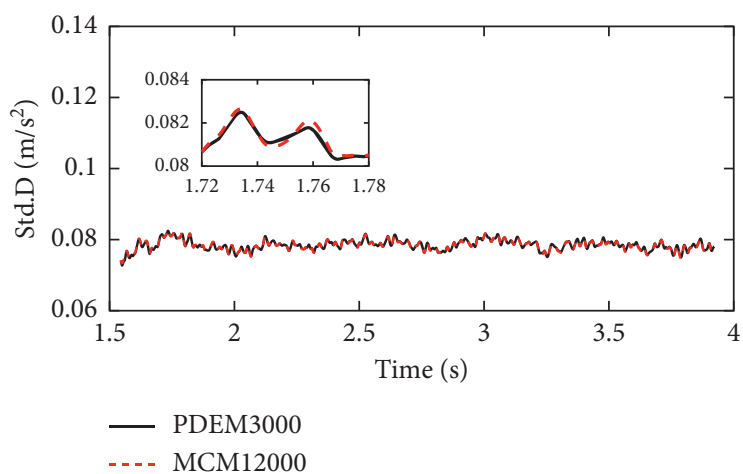

(c)

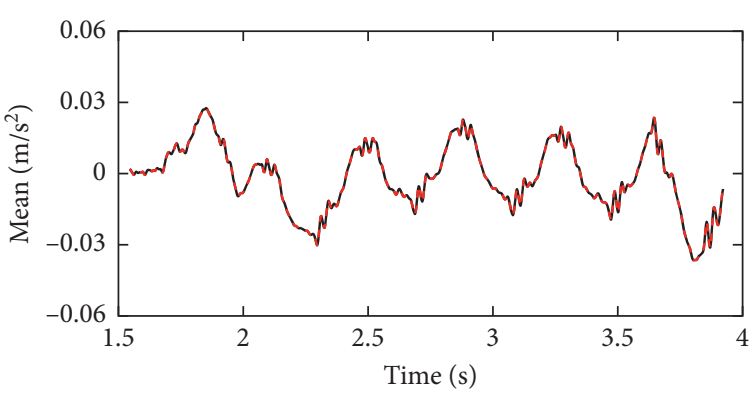

- PDEM3000

-..- MCM12000

(b)

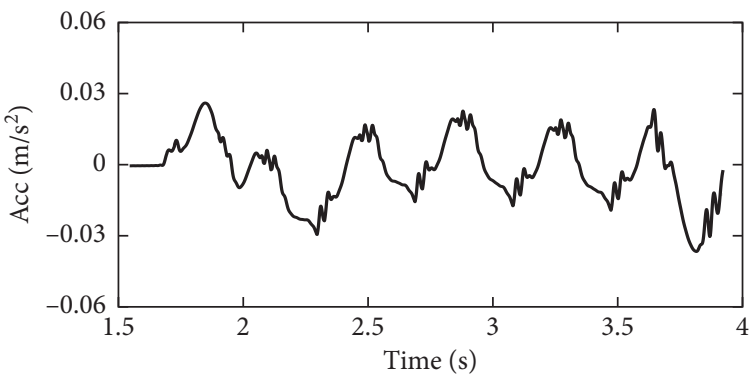

(d)

Figure 8: Statistical results of the vertical acceleration of the carbody: (a) PDF evolution against time; (b) mean; (c) Std. D; (d) no irregularities.

irregularities. Compared to the mean values in Figure 8(b), there are no obvious distinctions between them. It is further illustrated that the random field model of track irregularities presented in this paper is a good characterization of the stationary random process with second-order statistics.

5.2. Stochastic Analysis. In this section, two computational cases are set to quantitatively evaluate the influence of track random irregularities on system responses, namely, full PSD excitation and statistically average PSD excitation.

Figure 9 shows the statistical results of some representative dynamic indices including the lateral acceleration of the carbody, the wheel-rail lateral force, and the vertical acceleration at the middle of the central span. From the figures, it can be seen that no matter for the full PSD excitation or average PSD excitation, both the lateral acceleration of the carbody and the wheel-rail lateral force behave as stationary random processes, approximatively; however, with regard to the vertical acceleration at the middle of the central span, the mean value and Std. D fluctuates with the time-varying characteristics of trains running across the bridge. Besides, it can be observed from Figure 9 that if only the average PSD is considered in the stochastic dynamical analysis, the Std. D of three dynamic indices are significantly smaller than those excited by full PSD excitation. It seems to be inconsistent with the probability distribution of track irregularities. It may be because that the system responses are not linear with the quality of track irregularities. The worse the track irregularity quality is, the larger the increment of system responses is.

In addition, these figures provide information about the statistically quantitative values. For example, the Std. D of wheel-rail lateral force is about $5 \mathrm{kN}$ over time while its mean value is $1.5 \mathrm{kN}$. Apparently, the conventionally deterministic treatment is not sufficient to reveal the physical mechanisms of the random vibration of train-bridge systems or even erroneously evaluating the security.

In summary, the full excitation of track irregularities should be considered properly for evaluating the random behaviors of system components with higher precision.

\subsection{Reliability Analysis}

5.3.1. Reliability Analysis of Dynamic Indices. Based on the PDEM, the temporal reliabilities of arbitrary indices of the train-track-bridge system can be conveniently achieved. The same as stochastic analysis, the lateral acceleration of the carbody, the wheel-rail lateral force, and the vertical acceleration at the middle of the central span are selected as illustrations. Figures 10(a)-10(c) display the reliability curves versus time for the three indices, the safety threshold values of which are $0.6 \mathrm{~m} / \mathrm{s}^{2}, 10+P_{0} / 3 \mathrm{kN}$, and $3.5 \mathrm{~m} / \mathrm{s}^{2}$, respectively $[39,40] . P_{0}$ is the static axle load. As observed 


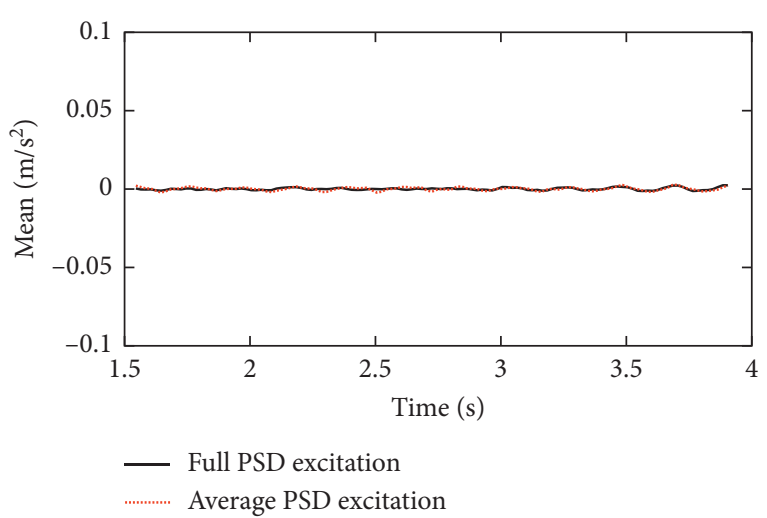

(a)

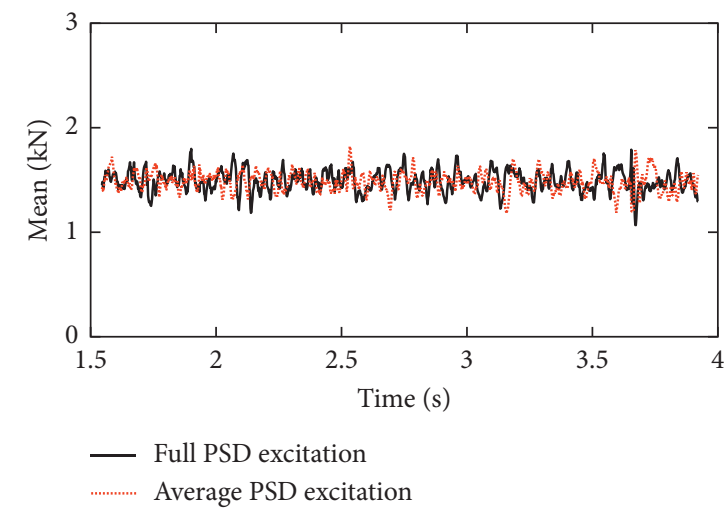

(c)

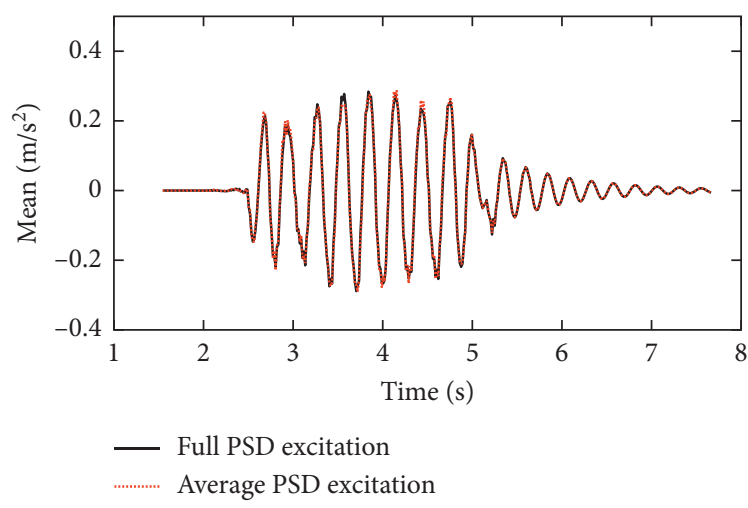

(e)

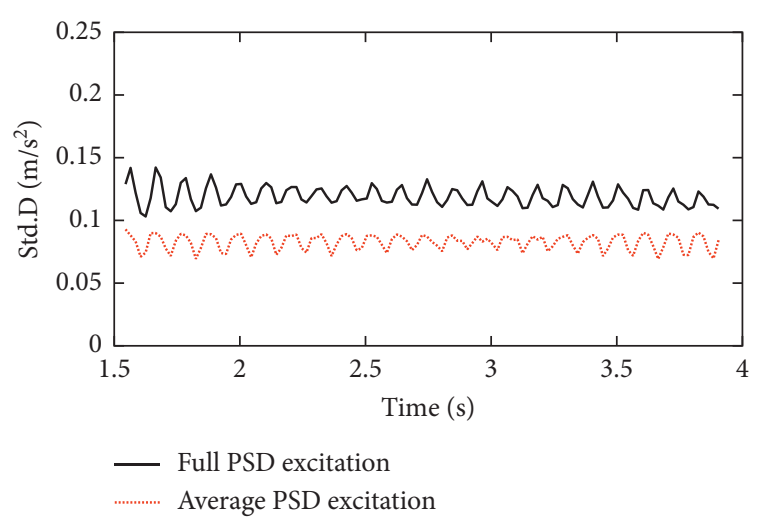

(b)

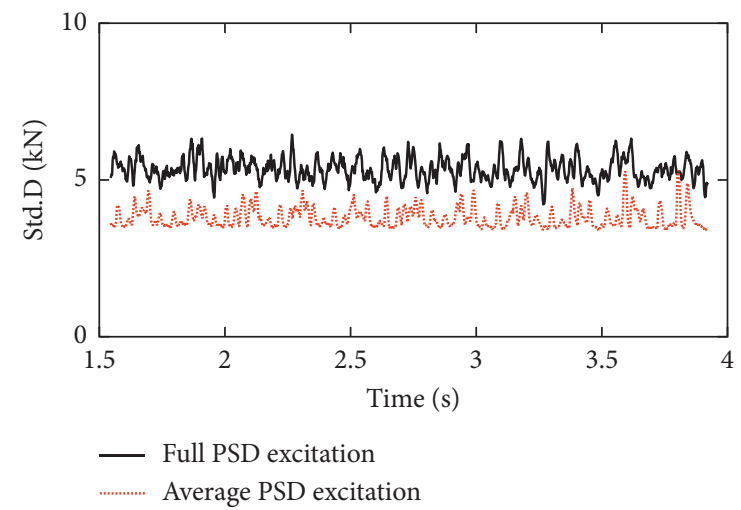

(d)

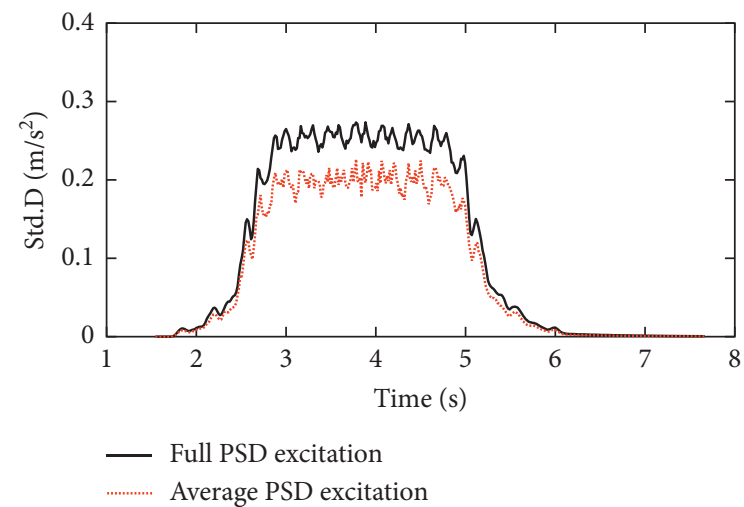

(f)

Figure 9: The time-domain mean and Std. D of different dynamic indices. (a, b) Lateral carbody acceleration; (c, d) wheel-rail lateral force; $(\mathrm{e}, \mathrm{f})$ vertical acceleration at the middle of the central span.

from the figures, their average reliabilities are around $98.7 \%$, $99.9 \%$, and $100 \%$, respectively. Generally, the threshold of lateral acceleration of the carbody is represented as the serviceability limiting state to ensure the comfort of passengers, while the limits of wheel-rail lateral force and deck acceleration are set as the ultimate limiting state to prevent train derailment and guarantee the stability of interlocking of the ballast gravel, respectively. In accordance with the common sense, the serviceability limiting state has lower reliability than the ultimate limiting state. It is worth pointing out that the above limit values are valued based on the existing specification, and they already contain a high safety factor. Therefore, the actual reliabilities are much higher than the values here.

5.3.2. System Failure Probability. With the reliability results for each dynamic index above, the system failure probability can be further determined by considering the contributions from different dynamic indices exceeding their respective limiting values. Assuming the train-track-bridge coupled system as a series system, the first-order estimates of the upper and lower bounds on the probability of system failure can be expressed as follows [41, 42]: 


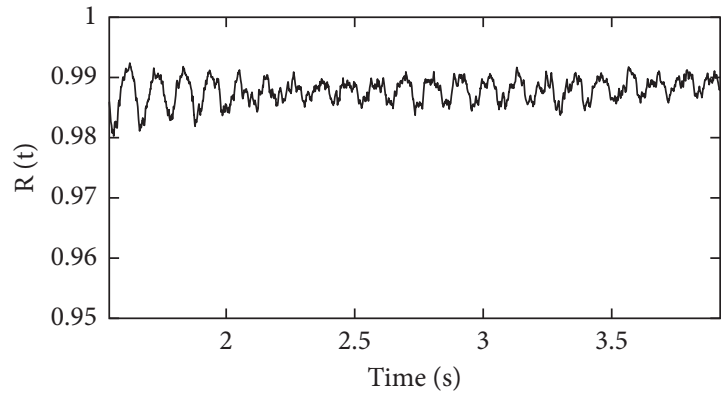

(a)

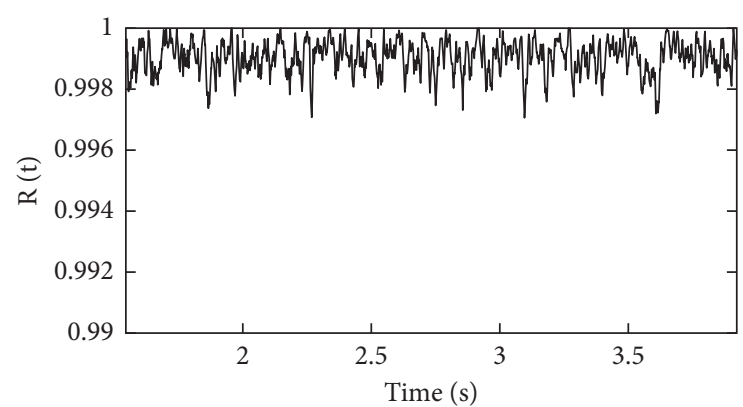

(b)

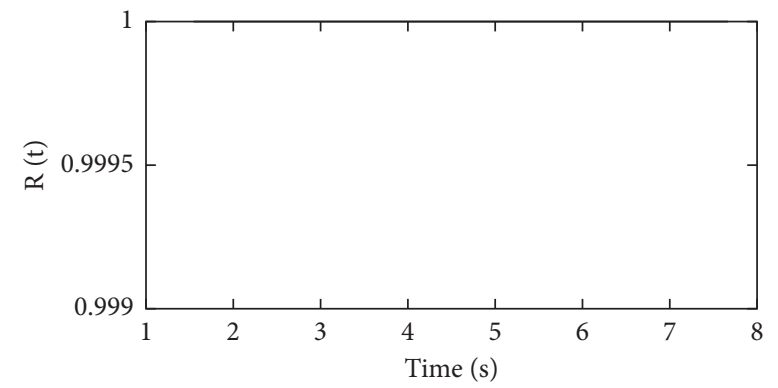

(c)

Figure 10: Reliability results of different dynamic indices: (a) lateral carbody acceleration; (b) wheel-rail vertical force; (c) vertical acceleration at the middle of the central span.

$$
\max _{i=1}^{m}\left[P_{F i}(t)\right] \leq P_{F, s}(t) \leq 1-\prod_{i=1}^{m}\left[1-P_{F i}(t)\right],
$$

with $P_{F i}(t)=1-R_{X, i}(t)$, where $P_{F i}(t)$ denotes the probability of failure for $i$ th index and is a function of time. For independent failure modes, the system failure probability can be represented as a function of the product of the mode survival probabilities, which provides the upper bound in equation (21). In cases where the failure modes are all fully dependent, the weakest failure mode will always be the most likely to fail, leading to the lower bound in equation (21).

Based on the first-order reliability theory, the probability of failure for the train-bridge system under the random field of track irregularities can be achieved, as shown in Figure 11. Several failure modes listed in Table 3 are considered in the evaluation. It can be seen from the figure that the differences between the upper and lower bounds are pretty slight, which indicates that it is appropriate to employ the first-order bounds to construct the system failure probability represented by the conservative estimate from the upper bounds. The failure probability is very small, with an average value of 0.02 , and general quality can be guaranteed for both running safety and ride comfort in this railway line. Furthermore, one would expect that using a single dynamic index (e.g., deck acceleration) would result in an underestimation of the train-track-bridge system's vulnerability.

5.4. Correlation Analysis. Excited by the temporal-spatial track irregularities, there might be a specific probability correlation among different dynamic indices. To mutually evaluate and predict their dynamic responses, a probabilistic relation analysis is highly essential. The procedure for revealing the response relationships between arbitrary two indices is as follows.

The responses of the dynamic indices denoted by $w_{i}$, $i=1,2, \ldots, n$, can be represented as $q_{w i}(k \Delta t), k=1,2, \ldots, m$, where $m$ is the total number of discrete points and $\Delta t$ is the time-domain integration interval for train-track-bridge interactions. For brevity, we take $w_{x}$ and $w_{y}$ as an example, where $x, y \in[1, n]$. To exclude the impact of data dimensions, the data are first normalized as

$$
\begin{aligned}
& \tilde{q}_{w x}=\frac{q_{w x}(k \Delta t)}{q_{w x, u}}, \\
& \tilde{q}_{w y}=\frac{q_{w y}(k \Delta t)}{q_{w y, u}},
\end{aligned}
$$

where $q_{w x, u}$ and $q_{w y, u}$ are the upper bounds of $q_{w x}(k \Delta t)$ and $q_{w y}(k \Delta t)$, respectively.

Meanwhile, $q_{w x}(k \Delta t)$ can be divided into $\alpha$ portions and expressed as follows:

$$
G_{i}=\frac{q_{w x, l}}{q_{w x, u}}+\frac{i}{\alpha q_{w x, u}}\left(q_{w x, u}-q_{w x, l}\right) ; \quad i=1,2, \ldots, \alpha,
$$

where $\alpha$ is the total partition number and $q_{w x, l}$ is the lower bound of $q_{w x}(k \Delta t)$.

For every response series of $q_{w x}(k \Delta t)$ and $q_{w y}(k \Delta t)$, it is clear that there is $q_{w y}(\widetilde{k} \Delta t), \widetilde{k} \in k$, located at the $i$ th interval $\left[G_{i-1}, G_{i}\right]$. Based on the methods of probability statistics [43], the PDF of $\widetilde{q}_{w y}$ specified to the interval $\left[G_{i-1}, G_{i}\right]$ can be written as 


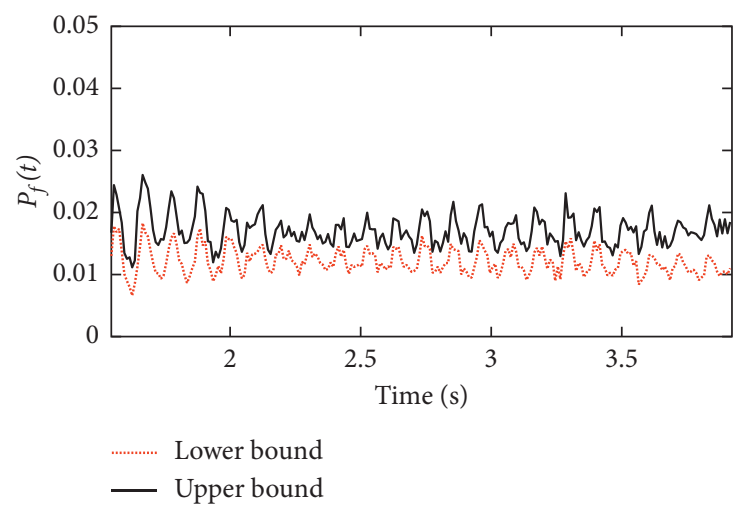

Figure 11: Probability of failure for the whole system.

TABLE 3: Maximum values for the main dynamic indices.

\begin{tabular}{lcc}
\hline Subsystem & Dynamic indices & Limiting value \\
\hline \multirow{2}{*}{ Vehicle } & Vertical acceleration of the carbody & $1 \mathrm{~m} / \mathrm{s}^{2}$ \\
& Lateral acceleration of the carbody & $0.6 \mathrm{~m} / \mathrm{s}^{2}$ \\
Wheel-rail interaction & Wheel-rail vertical force & $170 \mathrm{kN}$ \\
Bridge & Wheel-rail lateral force & $10+P_{0} / 3=62.3 \mathrm{kN}$ \\
& Vertical acceleration at the middle of the central span & $3.5 \mathrm{~m} / \mathrm{s}^{2}$ \\
& Lateral acceleration at the middle of the central span & $1.4 \mathrm{~m} / \mathrm{s}^{2}$ \\
\hline
\end{tabular}

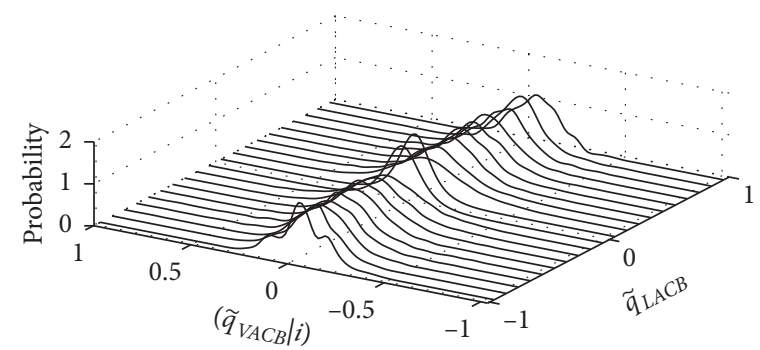

(a)

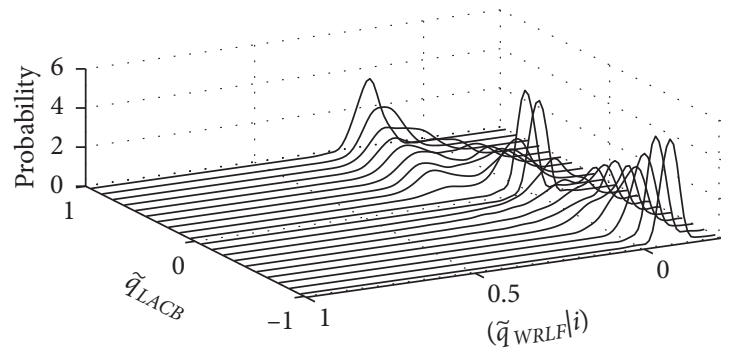

(b)

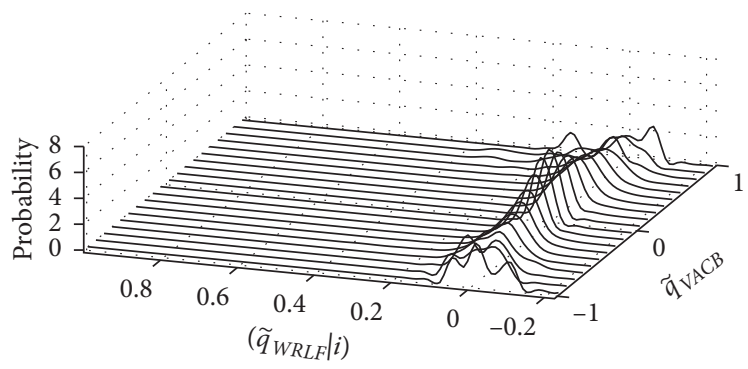

(c)

FIGURE 12: Probabilistic relations among some dynamic indices: (a) between vertical and lateral accelerations of the carbody; (b) between the lateral acceleration of the carbody and the wheel-rail lateral force; (c) between the vertical acceleration of the carbody and the wheel-rail lateral force.

$$
p_{\Omega_{x}, \Omega_{y}}\left(\widetilde{q}_{w y} \mid i\right)=\frac{\int_{G_{i-1}}^{G_{i}} f_{\Omega_{x}, \Omega_{y}}\left(\tilde{q}_{w x}, \tilde{q}_{w y}\right) \mathrm{d} \tilde{q}_{w x}}{\int_{G_{i-1}}^{G_{i}} \int_{\Omega_{y}} f_{\Omega_{x}, \Omega_{y}}\left(\widetilde{q}_{w x}, \widetilde{q}_{w y}\right) \mathrm{d} \tilde{q}_{w y} \mathrm{~d} \tilde{q}_{w x}},
$$

where $f_{\Omega_{x}, \Omega_{y}}\left(\widetilde{q}_{w x}, \widetilde{q}_{w y}\right)$ is the joint PDF of $\widetilde{q}_{w x}$ and $\widetilde{q}_{w y}$ and $\Omega_{x}$ and $\Omega_{y}$ denote the response amplitude range of $\widetilde{q}_{w x}$ and $\widetilde{q}_{w y}$, respectively.

For instance, Figure 12 shows the probabilistic relationships among some dynamic indices: 
(1) The relation between the lateral and vertical acceleration of carbody, as shown in Figure 12(a)

(2) The relation between the lateral acceleration of the carbody and the wheel-rail lateral force, as shown in Figure 12(b)

(3) The relation between the vertical acceleration of the carbody and the wheel-rail lateral force, as shown in Figure 12(c)

Out of convenience, the lateral acceleration of the carbody, the vertical acceleration of the carbody, and the wheel-rail lateral force are abbreviated as "LACB," "VACB," and "WRLF," respectively. It can be seen from the figures that no significant probability flow occurs between LACB and VACB and between VACB and WRLF, while WRLF specified to the maximum probabilities is slightly increasing along with the increments of LACB. It is because that, in light of different dynamic indices, the sensitive factors are rather different. For example, the magnitude of VACB is mainly affected by vertical profile irregularities, but LACB is significantly influenced by alignment irregularities; although WRLF is one of the sources for LACB, the WRLF is rather sensitive to the short-wavelength irregularities while $\mathrm{LACB}$ is sensitive to the long-wavelength irregularities [44]. According to the theory of random process, this indicates that there are no obvious or only weak probabilistic correlations among them, and correspondingly, they can be considered as mutually independent processes. Based on this understanding, the failure modes for these two indices are individual and independent. The upper bound of system reliability determined in Section 5.3.2 is appropriate.

\section{Conclusions}

This paper introduces a 3D train-track-bridge coupled system with nonlinear wheel-rail interactions first. Then, a probabilistic model is proposed to represent both spatial and spectral randomness of track irregularities. By combining these two models and PDEM, extensive studies are conducted on stochastic analysis, reliability analysis, and correlation analysis. The following remarks can be drawn from the results thereby obtained:

(1) The full probability characteristics of track irregularities should be considered when assessing the random vibrations of train-bridge systems.

(2) An accurate determination of the dynamic reliability of train-bridge systems has been achieved in a convenient manner. A full picture has been obtained of the PDF surfaces of the dynamic indices and of the dynamic reliability of the entire system versus time.

(3) Since the main contributive factors with respect to different dynamic indices are rather different, such as track irregularity type and wavelength, different failure modes can be assumed as mutually independent processes from the probabilistic perspective.

\section{Data Availability}

The track irregularity data used to support the findings of this study were supplied by Lifeng Xin under license and so cannot be made freely available. Requests for access to these data should be made to him, e-mail: sxxlf2010@163.com.

\section{Conflicts of Interest}

The authors declare that they have no conflicts of interest.

\section{Acknowledgments}

This work was supported by the National Natural Science Foundation of China under Grant numbers U1434205 and 51678490, Zhejiang Provincial Natural Science Foundation of China under Grant number LY19E080016, and Education of Zhejiang Province of China under Grant number Y201840370.

\section{References}

[1] A. Hamid and T. L. Yang, "Analytical descriptions of trackgeometry variations," Transportation Research Record, vol. 838, pp. 19-26, 1982.

[2] H. Claus and W. Schiehlen, "Modeling and simulation of railway bogie structural vibrations," Vehicle System Dynamics, vol. 29 , no. 1 , pp. 538-552, 1998.

[3] W. Zhai, K. Wang, and C. Cai, "Fundamentals of vehicle-track coupled dynamics," Vehicle System Dynamics, vol. 47, no. 11, pp. 1349-1376, 2009.

[4] R. H. Fries and B. M. Coffey, "A state-space approach to the synthesis of random vertical and crosslevel rail irregularities," Journal of Dynamic Systems, Measurement, and Control, vol. 112, no. 1, pp. 83-87, 1990.

[5] M. Majka and M. Hartnett, "Dynamic response of bridges to moving trains: a study on effects of random track irregularities and bridge skewness," Computers \& Structures, vol. 87, no. 1920, pp. 1233-1252, 2009.

[6] M. Zhu, X. Cheng, L. Miao, X. Sun, and S. Wang, "Advanced stochastic modeling of railway track irregularities," Advances in Mechanical Engineering, vol. 5, Article ID 401637, 2013.

[7] G. Perrin, C. Soize, D. Duhamel, and C. Funfschilling, "Track irregularities stochastic modeling," Probabilistic Engineering Mechanics, vol. 34, pp. 123-130, 2013.

[8] G. Perrin, D. Duhamel, C. Soize, and C. Funfschilling, "Quantification of the influence of the track geometry variability on the train dynamics," Mechanical Systems and Signal Processing, vol. 60-61, pp. 945-957, 2015.

[9] C. Funfschilling, G. Perrin, and S. Kraft, "Propagation of variability in railway dynamic simulations: application to virtual homologation," Vehicle System Dynamics, vol. 50, pp. 245-261, 2012.

[10] A. M. Panunzio, G. Puel, R. Cottereau, S. Simon, and X. Quost, "Construction of a stochastic model of track geometry irregularities and validation through experimental measurements of dynamic loading," Vehicle System Dynamics, vol. 55, no. 3, pp. 399-426, 2017.

[11] L. Xu, W. Zhai, and J. Gao, "A probabilistic model for track random irregularities in vehicle/track coupled dynamics," Applied Mathematical Modelling, vol. 51, pp. 145-158, 2017.

[12] L. Xu and W. Zhai, "Probabilistic assessment of railway vehicle-curved track systems considering track random 
irregularities," Vehicle System Dynamics, vol. 56, no. 10, pp. 1552-1576, 2018.

[13] P. K. Chatterjee, T. K. Datta, and C. S. Surana, "Vibration of continuous bridges under moving vehicles," Journal of Sound and Vibration, vol. 169, no. 5, pp. 619-632, 1994.

[14] F. T. K. Au, J. J. Wang, and Y. K. Cheung, "Impact study of cable-stayed railway bridges with random rail irregularities," Engineering Structures, vol. 24, no. 5, pp. 529-541, 2002.

[15] H. Xia and N. Zhang, Dynamic Interaction of Vehicles and Structures, Science Press, Beijing, China, Chinese, 2005.

[16] X. Liu, L. Jiang, Z. Lai, P. Xiang, and Y. Chen, "Sensitivity and dynamic analysis of train-bridge coupled system with multiple random factors," Engineering Structures, vol. 221, Article ID 111083, 2020.

[17] X. Liu, P. Xiang, L. Jiang, Z. Lai, T. Zhou, and Y. Chen, "Stochastic analysis of train-bridge system using the $\mathrm{kl}$ expansion and the point estimate method," Article ID 2050025, 2020.

[18] Z. C. Zhang, J. H. Lin, Y. H. Zhang, W. P. Howson, and F. W. Williams, "Non-stationary random vibration analysis of three-dimensional train-bridge systems," Vehicle System Dynamics, vol. 48, no. 4, pp. 457-480, 2010.

[19] X. Li, Y. Zhu, and Z. Jin, "Nonstationary random vibration performance of train-bridge coupling system with vertical track irregularity," Shock and Vibration, vol. 2016, Article ID 1450895, 19 pages, 2016.

[20] Y. Zhu, X. Li, and Z. Jin, "Three-dimensional random vibrations of a high-speed-train-bridge time-varying system with track irregularities," Proceedings of the Institution of Mechanical Engineers-Part F: Journal of Rail and Rapid Transit, vol. 230, no. 8, pp. 1851-1876, 2016.

[21] Z. Zeng, Z. Yu, Y. Zhao, W. T. Xu, L. K. Chen, and P. Lou, "Numerical simulation of vertical random vibration of trainslab track-bridge interaction system by PEM," Shock and Vibration, vol. 2014, Article ID 304219, 21 pages, 2014.

[22] J. M. Rocha, A. A. Henriques, and R. Calçada, "Safety assessment of a short span railway bridge for high-speed traffic using simulation techniques," Engineering Structures, vol. 40, pp. 141-154, 2012.

[23] J. M. Rocha, A. A. Henriques, and R. Calçada, "Probabilistic safety assessment of a short span high-speed railway bridge," Engineering Structures, vol. 71, pp. 99-111, 2014.

[24] J. M. Rocha, A. A. Henriques, R. Calçada, and A. Rönnquist, "Efficient methodology for the probabilistic safety assessment of high-speed railway bridges," Engineering Structures, vol. 101, pp. 138-149, 2015.

[25] P. Salcher, H. Pradlwarter, and C. Adam, "Reliability assessment of railway bridges subjected to high-speed trains considering the effects of seasonal temperature changes," Engineering Structures, vol. 126, pp. 712-724, 2016.

[26] Z. W. Yu, J. F. Mao, F. Q. Guo, and W. Guo, "Non-stationary random vibration analysis of a $3 \mathrm{D}$ train-bridge system using the probability density evolution method," Journal of Sound and Vibration, vol. 366, pp. 173-189, 2016.

[27] J. Mao, Z. Yu, Y. Xiao, C. Jin, and Y. Bai, "Random dynamic analysis of a train-bridge coupled system involving random system parameters based on probability density evolution method," Probabilistic Engineering Mechanics, vol. 46, pp. 48-61, 2016.

[28] Z. Jin, G. Li, S. Pei, and H. Liu, "Vehicle-induced random vibration of railway bridges: a spectral approach," International Journal of Reality Therapy, vol. 5, no. 4, pp. 191-212, 2017.
[29] D. Cantero, T. Arvidsson, E. Obrien, and R. Karoumi, "Traintrack-bridge modelling and review of parameters," Structure and Infrastructure Engineering, vol. 12, no. 9, pp. 1051-1064, 2016.

[30] G. Chen and W. M. Zhai, "A new wheel/rail spatially dynamic coupling model and its verification," Vehicle System Dynamics, vol. 41, no. 4, pp. 301-322, 2004.

[31] W. Zhai, H. Xia, C. Cai et al., "High-speed train-track-bridge dynamic interactions-Part I: theoretical model and numerical simulation," International Journal Railway Transportation, vol. 1, no. 1-2, pp. 3-24, 2013.

[32] W. Zhai, Z. Han, Z. Chen, L. Ling, and S. Zhu, "Train-trackbridge dynamic interaction: a state-of-the-art review," Vehicle System Dynamics, vol. 57, no. 7, pp. 984-1027, 2019.

[33] M. Shinozuka and G. Deodatis, "Simulation of stochastic processes by spectral representation," Applied Mechanics Reviews, vol. 44, no. 4, pp. 191-204, 1991.

[34] Z. Liu, W. Liu, and Y. Peng, "Random function based spectral representation of stationary and non-stationary stochastic processes," Probabilistic Engineering Mechanics, vol. 45, pp. 115-126, 2016.

[35] K. T. Fang and D. K. J. Lin, Uniform Design in Computer and Physical Experiments. The Grammar of Technology Development, Springer, Tokyo, Japan, 2008.

[36] J. S. Park, "Optimal Latin-hypercube designs for computer experiments," Journal of Statistical Planning and Inference, vol. 39, no. 1, pp. 95-111, 1994.

[37] J. B. Chen and J. Li, "Dynamic response and reliability analysis of non-linear stochastic structures," Probabilistic Engineering Mechanics, vol. 20, no. 1, pp. 33-44, 2005.

[38] J. Li and J. B. Chen, "Probability density evolution method for dynamic response analysis of structures with uncertain parameters," Computational Mechanics, vol. 34, no. 5, pp. 400-409, 2004.

[39] Rail 120, Code for Rating Existing Railway Bridges, China Railway Press, Beijing, China, 2004, In Chinese.

[40] EN1990, Eurocode 0: Basis of Structural Design-Amendment 1: Application for Bridges, European Committee for Standardization, CEN, Brussels, Belgium, 2002.

[41] C. A. Cornell, "Bounds on the reliability of structural systems," Journal of the Structural Division, vol. 93, no. 1, pp. 171-200, 1967.

[42] Y. T. Wu, "Computational methods for efficient structural reliability and reliability sensitivity analysis," AIAA Journal, vol. 32, no. 8, pp. 1717-1723, 1994.

[43] B. S. Turner, The Cambridge Dictionary of Sociology, Cambridge University Press, Cambridge, UK, 2006.

[44] L. Xin, X. Li, Y. Zhu, and M. Liu, "Uncertainty and sensitivity analysis for train-ballasted track-bridge system," Vehicle System Dynamics, vol. 58, pp. 1-19, 2019. 